University of Nebraska - Lincoln

DigitalCommons@University of Nebraska - Lincoln

Faculty Publications, Department of Psychology

Psychology, Department of

$1-1-2007$

\title{
Granny, (Don't) Get Your Gun: Competency Issues in Gun Ownership by Older Adults
}

\author{
Edith Greene \\ University of Colorado at Colorado Springs, egreene@uccs.edu \\ Brian H. Bornstein \\ University of Nebraska-Lincoln, bbornstein2@unl.edu \\ Hannah Dietrich \\ University of Colorado-Colorado Springs
}

Follow this and additional works at: https://digitalcommons.unl.edu/psychfacpub

Part of the Psychiatry and Psychology Commons

Greene, Edith; Bornstein, Brian H.; and Dietrich, Hannah, "Granny, (Don't) Get Your Gun: Competency Issues in Gun Ownership by Older Adults" (2007). Faculty Publications, Department of Psychology. 328.

https://digitalcommons.unl.edu/psychfacpub/328

This Article is brought to you for free and open access by the Psychology, Department of at DigitalCommons@University of Nebraska - Lincoln. It has been accepted for inclusion in Faculty Publications, Department of Psychology by an authorized administrator of DigitalCommons@University of Nebraska - Lincoln. 


\title{
Granny, (Don't) Get Your Gun: Competency Issues in Gun Ownership by Older Adults
}

\author{
Edith Greene, Ph. D., ${ }^{*}$ Brian H. Bornstein, Ph. D., ${ }^{\dagger}$ \\ and Hannah Dietrich, M. A. ${ }^{\ddagger}$ \\ * Department of Psychology, University of Colorado at Colorado Springs, \\ P. O. Box 7150, Colorado Springs, CO 80933, USA \\ Email: egreene@uccs.edu (Corresponding author) \\ ${ }^{\dagger}$ University of Nebraska-Lincoln. \\ ‡ University of Colorado-Colorado Springs.
}

\begin{abstract}
This article explores the possible risks associated with gun ownership by older adults. We summarize existing regulations on who may own firearms, especially with respect to age. We then present data on older gun owners and violence committed by older adults in general, followed by a discussion of gun violence perpetrated by gun owners whose functional and cognitive abilities have declined, perhaps as a result of dementia. For comparison purposes, we review regulations on driving among older adults, drawing parallels to gun ownership. The paper concludes with recommendations for ensuring the safety of older gun owners and others, balanced against citizens' right to bear arms, and with some directions for research.
\end{abstract}

The American population is aging. U.S. Census data show that, as of July, 2003, 35.9 million Americans (12\% of the population) were age 65 or over, 12.9 million were at least 75 , and 4.7 million were at least 85 years old. ${ }^{1}$ Current demographic trends suggest, moreover, that the proportion of older adults is increasing, and that "The older population is on the threshold of a boom." ${ }^{2}$ Many issues arise as the country prepares to deal with a larger number of older citizens: increasing healthcare costs, the availability of affordable long-term care, when workers should retire and how to fund retirement, accommodating older workers in the workplace, and so forth.

Some of these issues implicate the competency ${ }^{3}$ of older adults, such as their competency to make medical decisions, execute a will, live independently, and perform certain routine tasks, and various policies have been implemented to address these issues. For

1 Wan He et al., 65+ in the U.S. : 2005, at 15; issued December 2005 by the U.S. Dept. of Health and Human Services; available at http://www. census. gov/prod/2006pubs/p23-209. pdf

2 Id.

3 Competency is a legal term that refers, generally, to legal fitness to perform a certain act. Competency is determined by a judge. In this article, we also use the term "capacity, " a clinical term that describes specific decisional abilities that are assessed by mental health professionals. See, e.g., Jennifer Moye, "Assessment of Competency and Decision Making Capacity," in Handbook of Assessment in Clinical Gerontology (P. A. Lichtenberg, ed., 1999); Thomas Grisso, Evaluating Competencies: Forensic Assessments and Instruments (2003). 
example, some states have implemented policies requiring older drivers to renew their licenses more frequently, out of concern that older drivers' diminished cognitive-perceptual skills might make them more accident prone. Studies show that, statistically, older drivers are no more likely to have accidents than younger drivers, though they are more likely to be involved in fatal accidents per mile driven (infra). Thus, attention must be paid to impaired older drivers in the same way that attention must be paid to any other drivers who might pose an increased risk.

The most common threat to competency in older adults is loss of cognitive and functional abilities, sometimes (though not always) leading to a diagnosis of dementia. The rationale behind tighter regulation of older adults' driving is to reduce risks to themselves and others that arise as faculties and cognitive abilities decline. There are other behavioral domains where aging, and especially age-related dementia, likewise poses significant risks, but that are not regulated. The present paper explores one such domain, namely, gun ownership by older adults.

Gun ownership among older adults is important for several reasons. First, gun ownership in the U.S. is apparently growing faster among older adults than among any other age group, ${ }^{4}$ and according to a Canadian study, the older a person, the more likely he or she is to own a gun. 5 Thus, there are likely to be many cases of older adult gun owners who were licensed to purchase guns when they were younger and who still have these guns. Second, as noted above, the population is aging, and this trend is accompanied by an increase in the number of individuals experiencing functional and cognitive impairment, sometimes resulting in dementia. The possibility that demented persons possess firearms is cause for concern. Third, unlike other domains, such as driving and piloting a plane, there are few procedures for regulating older gun owners or ensuring that they maintain their ability to use guns safely. Other regulations on who may own firearms exist, ${ }^{6}$ and it is therefore worth considering whether these regulations should be expanded to include certain older adults as well.7 Our analysis will focus, in particular, on those individuals whose faculties are in decline but who have not been adjudicated in a court of law as incompetent. ${ }^{8}$

This article explores the possible risks associated with gun ownership by older adults. ${ }^{9}$ The following section briefly summarizes existing regulations on who may own

4 Tim Vanderpool, Why More Senior Citizens are Carrying Guns, Christian Science Monitor, Jan. 06, 2004; available at http://www. csmonitor. com/2004/0106/po2so1-ussc. html

5 Phillip Stenning \& Sharon Moyer, Firearms Ownership and Use in Canada: A Report of Survey Findings, 1976, National Criminal Justice Reference Service Report 086325, U.S. Dept. of Justice, Washington, DC (1981).

6 The Gun Control Act of 1968 prohibits nine classes of people from possessing firearms: those convicted of a crime punishable by imprisonment for more than one year; fugitives from justice; drug users or addicts; persons adjudicated mentally defective (i.e. legally incompetent) or committed to mental institutions; unauthorized immigrants; those dishonorably discharged from the military; those who have renounced U.S. citizenship; persons with restraining orders related to domestic violence; and persons convicted of misdemeanor domestic violence (18 U.S. C. § 922). Various state laws also prohibit gun ownership by people with mental illness, including those in outpatient treatment or civilly committed to treatment, substance abusers, and individuals found not guilty by reason of insanity. Eve Bender, Most States Say Mental Illness Reason to Bar Gun Ownership, 41 Psychiatr. News 6 (2006).

7 We are not advocating a maximum age for gun ownership, infra note 13 .

8 Those deemed legally incompetent are already restricted from gun possession, supra note 6 .

9 It is not our purpose to make any of several radical, inflammatory proposals, such as that older adults should simply not be allowed to own guns. We have no intention to attack the Second Amendment's guarantee of the right to bear arms. However, given that it is constitutionally permissible to regulate that right, and given the significant risks we identify in the article, we do argue that additional regulation might be appropriate. 
firearms. The next section then presents data on older gun owners and violence committed by older adults. The third section describes the prevalence of dementia and legal standards for assessing competency in older adults, the implications these standards have for gun ownership, and the risks of violence perpetrated by demented gun owners. The fourth section reviews regulations on driving among older adults, drawing parallels to gun ownership. The fifth section sets out recommendations for ensuring the safety of older gun owners and others, balanced against citizens' right to bear arms, and suggests directions for future research. The sixth section concludes.

\section{Regulations on Gun Ownership}

What restrictions are there on gun purchase and ownership? There is a sizeable literature on the advisability of various restrictions on gun ownership, and the balancing of public safety and individual liberties guaranteed by the Second Amendment. ${ }^{10}$ It is not our purpose to enter into this debate. We support the moderate premises, accepted by most (though certainly not all) proponents and opponents of gun control, that (1) U.S. citizens, under most circumstances, have the right to bear arms and (2) there are circumstances and conditions that legitimately limit this right. In the present article, we address the loss of cognitive and functional capacity related to aging as a circumstance that may limit this right.

Certain classes of persons are ineligible to possess, receive, or transport firearms. ${ }^{11}$ Although there are minimum ages for gun ownership, ${ }^{12}$ there is apparently no maximum age beyond which one may not purchase a firearm. ${ }^{13}$ Rather, the regulation most relevant to gun ownership among older adults is the Federal Gun Control Act of 1968, barring gun ownership by anyone who has been adjudicated as "mentally defective" or who has been committed to a mental institution. ${ }^{14}$ Thirty-three states currently restrict gun ownership for this reason. ${ }^{15}$

10 See, e.g., Richard M. Aborn, The Battle over the Brady Bill and the Future of Gun Control Advocacy, 22 Fordham Urb. L. J. 417 (1995); Jeffrey Monks, The End of Gun Control or Protection against Tyranny? The Impact of the New Wisconsin Constitutional Right to Bear Arms on State Gun Control Laws, 2001 WISc. L. Rev. 249 (2001). Interestingly, a report by the National Academies' National Research Council concludes that policy questions related to gun ownership and restrictions on possession of firearms cannot be answered definitively because of gaps in existing research. Charles Wellford et al. eds., Firearms and Violence: A Critical ReVIEW (2004).

11 Supra note 6.

12 Eighteen for a shotgun or rifle, 21 for other firearms, including handguns. See, e.g., the National Rifle Association's A Citizen's Guide to Federal Firearms Laws, available at http://nraila. org/GunLaws/Federal ; Survey of State Procedures Involving Firearm Sales Midyear 2003, Bureau of Justice Statistics, NCJ Report 203701, available at http://www. ojp. usdoj. gov/bjs/ pub/pdf/ssprfsmo3. pdf

13 Nor do we propose a maximum age for gun ownership, as this would unfairly discriminate against the large majority of older citizens whose competency is not in question. Rather, as discussed infra, we suggest a need to evaluate capacity with increasing age, in order to decrease the prevalence of incompetent gun owners.

14 Supra note 6. The Federal Gun Control Act serves as a minimum standard; state laws may exceed these mandates. See generally Survey of State Procedures Involving Firearm Sales Midyear 2003, supra note 12. The definition of "adjudicated as a mental defective" is a person who is found by a court to be a danger to himself or others or unable to manage his own affairs (i.e., legally incompetent).

15 Survey of State Procedures, supra note 12. 
There are three problems with this safeguard: first, as discussed infra, the vast majority of cognitively and functionally impaired persons (including those with dementia) do not receive a formal adjudication attesting to this fact, nor have they been committed to a mental institution. Second, for many patients with mild cognitive impairment or early dementia, competency is often not even questioned until they have committed some act that poses a risk to themselves or others. In other words, competency might not become an issue until it is already too late. Third, although a regulation barring firearm possession as a result of a "mental defect" might prevent gun purchases by an incompetent older adults (and some states have taken steps to address this possibility more directly ${ }^{16}$ ), it fails to address the much more likely scenario of diminished capacity in a person who already owns a firearm that he or she purchased when younger and more capable.

\section{Older Adults, Firearms, and Violence}

\section{Ownership and use of Firearms by Older Adults}

Gun ownership among older adults is increasing. For example, a 2004 Florida survey showed that more than 130, ooo of Florida's 338, ooo concealed carry permits had gone to persons over $50 .{ }^{17}$ U.S. citizens older than age 65 are now more likely than any other age group to own a gun, ${ }^{18}$ and many of them have concealed carry permits. ${ }^{19}$ The likelihood of gun ownership by Canadian citizens also increases with age. ${ }^{20}$ As among many gun owners, gun ownership by older adults is driven in part by fear of victimization and desire for protection. ${ }^{21}$ It is indisputable that the vast majority of gun owners are law abiding, but it is equally indisputable that in some cases firearms may be used to commit crimes rather than to defend against them. ${ }^{22}$

16 Infra.

17 Jacksonville, Florida Times-Union, 10/7/04, New Senior Security: Guns. Cited by Massad Ayoob, Geezer Guns: Older Folks Need Guns More, and Sometimes Their Choice Needs Tailoring, Guns MAGAZINE (March, 2005) at 22. Ayoob suggests that guns are the logical choice for warding off criminals by infirm and elderly people because their use requires little physical strength. He also describes the ways that guns can be retrofit for individuals with failing eyesight, arthritis and other ailments that affect finger strength, weak hands, and problems with recoil.

18 Vanderpool, supra note 4 (reporting results of the National Opinion Research Center's General Social Survey for 2000 and 2002).

19 E.g., Vanderpool cited an Arizona Department of Public Safety study showing that more than 31, ooo Arizona residents aged 50-69 had concealed-weapon permits, id., and Ayoob cited a Jacksonville (Fla.) TimEs-Union article stating that more than 130, ooo of Florida's concealedweapon permits went to persons over 50. Ayoob, supra note 17.

20 Stenning \& Moyer, supra note 5.

21 E.g., Sarah Dozier, the 75-year old niece of 92-year old Atlanta resident Kathryn Johnston, purchased a gun for her aunt that she intended to be used for protection. But when police with a warrant knocked down Johnston's door to search for drugs on November 21, 2006, she opened fire, wounding the three officers just before being shot to death herself. Available at http://www. cnn. com/2006/US/11/22/woman. shot. ap/index. html

22 We could find no good data on whether older adult gun owners are any more or less likely to use firearms illegally than gun owners in general. The data on crime rates as a function of perpetrator age (see infra) make it plausible to assume that, on the whole, they are less likely to use guns to commit a crime. 


\section{Violence by Older Adult Perpetrators}

Abundant research shows that older adults have considerably lower rates of criminal offending than other age groups. ${ }^{23}$ Most crimes committed by older adults, like most crimes overall, are non-violent. For example, an Israeli study of older adult criminals found that only $10.7 \%$ of the cases involved serious violence. ${ }^{24}$ Summaries of national arrest data "indicate that elderly persons are most often apprehended for the crimes of assault, embezzlement, fraud larceny-theft, alcohol-related offenses, and the 'less serious' sex offenses." ${ }^{25}$ Thus, although non-violent crimes are the norm, violent crimes, such as assault and sex offenses, are not uncommon. Consistent with these observations, Schichor and Kobrin report the surprising finding, based on Uniform Crime Reports statistics, that a higher proportion of offenders age 55 and over are arrested for violent crimes (27\%) than the total arrested population (20.0\%). ${ }^{26}$ Over $80 \%$ of these violent offenses were aggravated assault. ${ }^{27}$ They also found that the proportion of index offenses committed by those 55 and older increased during the study period (1964-1974) ${ }^{28}$ Thus, there is some evidence that crimes committed by older offenders, and especially violent crimes, are on the rise.

There have been several studies of older adult homicide offenders. ${ }^{29}$ For example, Professor Ann Goetting conducted a study of 45 homicide offenders aged 55-82 in Detroit, MI, during a two-year period. ${ }^{30}$ The offenders were disproportionately Black (88.9\%), male (88.9\%), unmarried, relatively uneducated, and unemployed. ${ }^{31}$ The larg-

23 See, e.g., David Schichor \& Solomon Kobrin, Criminal Behavior among the Elderly, 18 THE Gerontologist 213 (1978); Donald J. Newman, Elderly Criminals and American Crime Patterns, in Elderly Criminals (E. S. Newman et al. eds., 1984); Kenneth E. Gewerth, Elderly Offenders: A Review of Previous Research, in OldER OfFenders (B. McCarthy \& R. Langworthy eds., 1988). When older persons do commit crimes, they tend to receive more lenient sentences. Darrel Steffensmeier \& Mark Motivans, Older Men and Older Women in the Arms of Criminal Law: Offending Patterns and Sentencing Outcomes, 55B J. Gerontology S141 (2000). This leniency is apparent in both plea-bargaining agreements and sentences resulting from trial. E.g., in a study of six circuit court jurisdictions, Champion found that offenders aged 60 and over received plea-bargaining sentences less than half the length of those of their younger counterparts, and post-trial sentences were nearly a third as severe. Dean J. Champion, The Severity of Sentencing: Do Federal Judges Really Go Easier on Elderly Felons in Plea-Bargaining Negotiations Compared with Their Younger Counterparts? In OLDER OfFEnders (Belinda McCarthy \& Robert Langworthy, eds., 1988), at 154 .

24 Yorum Barak et al., Elderly Criminals: A Study of the First Criminal Offence in Old Age, 10 INTL. J Geriatric Psych. 511 (1995). This study also found that 50\% of older adult criminals suffered from some sort of neuropsychiatric disorder, including dementia. Violence by demented persons is discussed at greater length infra.

25 Gewerth, supra note 23, at 30.

26 Schichor \& Kobrin, supra note 23, at 214. See also David Schichor, The Extent and Nature of Lawbreaking by the Elderly: A Review of Arrest Statistics, in Elderly Criminals (E. S. Newman et al. eds., 1984).

27 Id.

28 Id. See also Schichor, supra note 26; Gewerth, supra note 23.

29 See, e.g., William Wilbanks \& Dennis D. Murphy, The Elderly Homicide Offender, in ELDERLY CRiminals (E. S. Newman et al., eds., 1984); Peter C. Kratcoski \& Donald B. Walker, Homicide Among the Elderly: Analysis of the Victim/Assailant Relationship, in OLdER OFFENDERS (B. McCarthy \& R. Langworthy, eds., 1988); Ann Goetting, Patterns of Homicide among the Elderly, 7 Violence \& Victims 203 (1992).

30 Goetting, supra note 29 at 204. The sample consisted of all homicide arrestees who satisfied the minimum age criterion during the study period.

31 Id. at 204-205. The vast majority of victims were also Black males. Other studies of older adult homicides have found similar demographic characteristics of perpetrators and victims; see note 29, supra . 
est proportion of victims (24.5\%) were strangers; the other relationship categories were spouses/romantic acquaintances (18.4\%), other relatives (18.4\%), casual acquaintances (18.4\%), and unrelated housemates or friends (20.4\%). ${ }^{32}$ In their analysis of 82 homicides committed by perpetrators age 60 and over in Cuyahoga County, $\mathrm{OH}$ (including Cleveland) from 1970 to 1983 , Kratcoski and Walker found a slightly different relationship pattern: only $10 \%$ of victims were strangers, while $24 \%$ were spouses (mostly wives), $9 \%$ were other relatives, and $57 \%$ were acquaintances. ${ }^{33}$ These findings suggest that, as with violent crimes in general, persons close to the perpetrator are at greatest risk. 34

Goetting also addressed the manner of killing: $79.6 \%$ were committed with firearms, a higher proportion than for Detroit homicides in general during the study period (65.8\%). ${ }^{35}$ Compared with younger violent offenders, older violent offenders are more likely to suffer from a functional mental disorder other than dementia, such as schizophrenia or paranoid psychosis. ${ }^{36}$

The substantial proportion of spousal relationships in the Goetting study underscores the high prevalence of intimate partner violence in the population of older adults. In a study of 1,245 postmenopausal (aged 50 and above) women in San Antonio, TX, Professor Charles Mouton found that between 5.2 and 22.8\% reported exposure to some type of abuse in the past 12 months, and 7.9\% reported exposure to gunrelated threats. ${ }^{37}$ Domestic violence against older adult victims, perpetrated most often by spouses, is grossly underreported and undertreated. ${ }^{38}$

Victims of gun violence can, of course, be the gun owners themselves. Older adults are more likely than younger people to commit suicide using a firearm. ${ }^{39}$ Yeates Conwell and colleagues analyzed suicides among people 50 and over in the Rochester and Syracuse, NY, areas between December 1996 and January 2001. Men over 50 who had a handgun in the home were more than twice as likely to kill themselves as comparable men without a handgun. ${ }^{\circ 0}$ A study conducted by Minnesota Department of Health

$32 \mathrm{Id}$. at 206.

33 Kratcoski \& Walker, supra note 29, at 70.

34 See also Arthur L. Kellermann et al., Gun Ownership as a Risk Factor for Homicide in the Home, 329 New Eng. J. Med. 1084 (1993), which found that keeping a gun in the home increased homicide risk 2.7-fold, and that most of those homicides were committed by a family member or intimate acquaintance.

35 Id. at 208. In the older adult sample, an additional 8.2\% each were stabbings and beatings, and $4.1 \%$ were burnings.

36 Stephen J. Hucker, Psychiatric Aspects of Crime in Old Age, in Elderly Criminals (E. S. Newman et al., eds., 1984), at 73. The role of dementia in older adult offenders is treated at length in the following section.

37 Charles P. Mouton, Intimate Partner Violence and Health Status among Older Women, 9 VIolence Against Women 1465 (2003). For discussion of the relationship between domestic violence fatalities and guns, see Sharon L. Gold, Why Are Victims of Domestic Violence Still Dying at the Hands of Their Abusers? Filling the Gap in State Domestic Violence Gun Laws, 91 Ky L. J. 935 (2003).

38 See, e.g., Ronet Bachman \& Karl A. Pillemer, Retirement: Does It Affect Marital Conflict and Violence? 3 J. ELdER Abuse \& NegLeCT 75 (1991); Jennifer Schaffer, Older and Isolated Women and Domestic Violence Project, 11 J. ELDER AbuSE \& NEGLECT 59 (1999).

39 Yeates Conwell et al., Access to Firearms and Risk for Suicide in Middle-Aged and Older Adults, 10 Am. J. Geriatr. Psych. 407 (2002). See also Arthur A. Slatkin, Suicide Risk and Hostage/Barricade Situations Involving Older Persons, 72 FBI Law ENForCement BulL. 26 (2003) (describing a case study of an averted elderly suicide and recommending strategies for dealing with such situations).

40 Conwell et al., supra note 39. The finding was less true for women and was limited to handguns; presence of a rifle or shotgun did not increase suicide risk. Other data suggest that the increased risk of suicide associated with having a gun in the home is even greater. See Arthur L. Kellermann et al., Suicide in the Home in Relation to Gun Ownership, 327 NEw EnG. J. MED. 467 (1992) (suggesting a nearly five times greater risk). 
tracked all firearms-related deaths in the state between 1998 and 2001 and concluded that people 65 and older and those between 15 and 24 had the highest rates of suicide from firearms. ${ }^{41}$

\section{Dementia, Firearm Access, and Safety Concerns}

\section{Dementia, Aggression, and Violence}

Dementia is a term used to describe the constellation of symptoms that occur when the brain is affected by conditions such as Alzheimer's disease (AD), strokes, and other less common diseases. Symptoms of dementia include memory loss, personality changes, confusion, speech and language problems, increased anxiety and aggressiveness, depression, and eventually, loss of bodily functions.

Alzheimer's disease, the most common form of dementia, is believed to be caused by chemical and structural changes in the brain that increase over time, cause functional impairments, and lead to debilitation and eventually to death. It is estimated that 4.5 million Americans suffered from AD in 2000 and that the number will increase threefold, to 13.2 million cases, by the year 2050, reflecting the fact that the risk of AD increases with advancing age and rapid growth in the number of the oldest-old in the U.S. population..$^{2}$

Vascular dementia, the second most common form of dementia and also progressive in nature, is related to a loss of blood supply to the brain. High cholesterol, diabetes, high blood pressure, and heart problems can all result in damage to the vascular system within the brain that can eventually result in dementia.

One of the most concerning symptoms of advanced stages of dementia is uncharacteristic and increased aggressiveness, and in some cases violent behavior. ${ }^{43}$ There is a high incidence of low level aggression among people with dementia, ${ }^{44}$ and more serious aggressive and violent acts, including self-harm and homicide, are not uncommon. 45

A series of studies of dementia-associated mental and behavioral disturbances examined 5,092 community residents, fully $90 \%$ of older adult residents of Cache County, $\mathrm{UT},{ }^{46}$ who were screened for dementia (AD, vascular dementia, and other dementia-related diagnoses) and rated on the Neuropsychiatric Inventory. Of the participants with dementia, $24 \%$ had exhibited agitation or aggression in the previous month, compared

41 Injury and Violence Prevention Unit, Firearm-Related Injury, Minnesota, 1998-2001. Minnesota Department of Health (2004), available at http://www. health. state. mn. us/injury/pub/ firearm. pdf

42 Liesi E. Hebert et al., Alzheimer's Disease in the U.S. Population: Prevalence Estimates using the 2000 Census, 10 Arch. Neurol. 1119 (2003).

43 The terms "aggression" and "violence" have various definitions. We use the term "violence" here to imply higher levels of intensity in the behaviors exhibited and in their lethality.

44 Dave Pulsford \& Joy Duxbury, Aggressive Behaviour by People with Dementia in Residential Care Settings: A Review, 13 J. Psychiatric Mental Health Nurs. 611 (2006).

45 S. DeYoung et al., Decreasing Aggressive, Agitated or Disruptive Behavior: Participation in a Behavior Management Unit, 28 J. Geront. Nurs. 22 (2002); Nick Hindley \& Harvey Gordon, The Elderly, Dementia, Aggression and Risk Assessment, 15 Int. J. Geriat. Psychiatry 254 (2000).

46 John Breitner et al., APOE-ع4 Count Predicts Age when Prevalence of AD Increases, then Declines: The Cache County Study, 53 Neurology 321 (1999); Constantine Lyketsos et al., Mental and Behavioral Disturbances in Dementia: Findings from the Cache County Study on Memory in Aging, 157 Aм. J. Psychiatry 708 (2000). 
with only $3 \%$ of a sample of non-demented matched controls. The prevalence of aggressive behaviors increased with advancing stages of dementia and was documented in $13 \%$ of cases of mild dementia, $24 \%$ of cases of moderate dementia, and $29 \%$ of cases of severe dementia.

The incidence of aggressive behavior has been shown to increase with increasing disease severity 47 and to be associated with moderate to severe depression, male gender, and greater impairment in the activities of daily living. ${ }^{48}$ Environmental stressors such as on-going conflicts with others and a sudden change in environment can also contribute to aggressive behaviors in elderly patients suffering from dementia. ${ }^{49} \mathrm{Ag}$ gression directed toward family members is a major reason that older adults are moved to residential care facilities, ${ }^{50}$ but physically aggressive behaviors are also common in these settings ${ }^{51}$ and can have significant emotional impact on professional staff. ${ }^{52}$

On occasion, these aggressive behaviors turn violent and result in criminal acts. Studies have shown that dementia results in the disinhibition of violent impulses, 53 that criminal behavior is more common in patients suffering from fronto-temporal dementia than from $\mathrm{AD}, 54$ and that dementia is more strongly associated with the commission of sexual offenses than non-sexual offenses. ${ }^{55} \mathrm{~A}$ retrospective study of 52 geriatric patients with dementia who required acute psychiatric hospitalization found that $44 \%$ had engaged in physical attacks and/or fear-inducing behavior in the two-week period prior to admission and that these behaviors were repeated during the first 72 hours of hospitalization by $29 \%$ of patients. ${ }^{56}$ Although dementia is not the sole explanation for violence in these cases, 57 it is nonetheless a major factor.

\section{Prevalence of Firearms Among Dementia Sufferers}

Relatively little is known about the prevalence of firearm ownership or about the risks related to firearms in dementia patients, although the risks of keeping loaded and readily accessible firearms in a home have been documented for other vulnerable populations, including children, individuals suffering from depression and substance abuse,

47 Joan M. Swearer et al., Troublesome and Disruptive Behaviors in Dementia. Relationship to Diagnosis and Disease Severity, 36 J. Am. Geriat. Soc. 784 (1988).

48 Constantine Lyketsos et al., Physical Aggression in Dementia Patients and its Relationship to Depression, 156 Am. J. Psychiatry 66 (1999).

49 Hindley \& Gordon, supra note 45; Pulsford \& Duxbury, supra note 44.

50 David W. Gilley et al., Influence of Behavioural Symptoms on Rates of Institutionalization for Persons with Alzheimer's Disease, 34 Psych. Med. 1129 (2004).

51 Hindley \& Gordon, supra note 45.

52 Will J. Evers et al., Aggressive Behaviour and Burnout among Staff of Homes for the Elderly, 11 Int. J. Of Mental Health Nurs. 2 (2002); V. Rodney, Nurse Stress Associated with Aggression in People with Dementia: Its Relationship to Hardiness, Cognitive Appraisal and Coping, 31 J. APPLIED NURS. 172 (2000).

53 Fernando G. Bozzola et al., Personality Changes in Alzheimer's Disease, 49 ArCh. Neurol. 297 (1992); Bob G. Knight, Geriatric Homicide, APR 1983 Geriatr. Med. 297 (1983).

54 Bruce L. Miller et al., Aggressive, Socially Disruptive and Antisocial Behaviour Associated with Front-Temporal Dementia, 170 BR. J. Psychiatry 150 (1997); David Neary et al., Dementia of Frontal Lobe Type, 51 J. Neurol. Neurosurg. Psychiatry 353 (1988).

55 Barbara M. Farragher, \& Art A. O'Connor, Forensic Psychiatry and Elderly People: A Retrospective Review, 35 Med. Sci. Law (1995); Jeremia Heinik et al., Dementia and Crime: A Forensic Psychiatric Unit Study in Israel, 9 Int. J. Geriatr. Psychiatry 491 (1994).

56 Ellen Haller et al., Violence in Geriatric Patients with Dementia, 17 Bull. Am. Psychiatry Law 183 (1989).

57 M. O'Connor, Disturbed Behaviour in Dementia-Psychiatric or Medical Problem? 147 Med. J. Australia 481. 
and those living in homes marked by domestic violence. ${ }^{8}$ It has been hypothesized that families of dementia patients living in the community might be especially sensitive to the presence of firearms in the homes of their older adult relatives and that they would preemptively remove or secure them. ${ }^{59}$ In fact, case studies ${ }^{60}$ and the sparse data that exist on this subject suggest otherwise.

For example, Mario Mendez ${ }^{61}$ reported the case of an 82-year old man who accidentally shot himself in the eye while responding to imaginary burglars in his home. The man had a 5-year history of memory difficulties, impairment in cognitive functioning, and compromised ability to perform the instrumental activities of daily living, and had been experiencing paranoid delusions during the preceding 8 months. He believed that intruders were in his house stealing his possessions, so he repeatedly checked his locks and stayed awake at night, pacing with a gun in hand.

A few empirical studies have documented the prevalence of gun ownership among dementia patients. For example, a report by the Office of Medical Inspector of the Department of Veterans' Affairs examined the relation between dementia in older veterans and their firearm practices. ${ }^{62}$ Veterans in 21 states who had previously been diagnosed with mild to moderate dementia and who had a recent cognitive status score to indicate the severity of their dementia were included in the study; $40 \%$ of them lived in homes in which firearms were present. There were no significant differences in mental status (as measured by the Mini-Mental Status Exam, MMSE ${ }^{6}$ ) in respondents with access to firearms and those without. Among respondents with firearms in the home, 25\% had a MMSE score that indicated moderate to severe dementia. Of those possessing firearms, $32 \%$ had access to a handgun, $43 \%$ had access to another kind of gun, $25 \%$ had access to both, and $77 \%$ had ammunition available. Approximately one-fifth (21\%) of respondents stored loaded guns and $73 \%$ stored guns unloaded, though only approx-

58 David A. Brent et al., The Presence and Accessibility of Firearms in the Home of Adolescent Suicides: A Case-Control Study, 266 J. A. M. A. 2989 (1992); Arthur L. Kellerman et al., Gun Ownership as a Risk Factor for Homicide in the Home, 329 N. EnGL. J. MED. 1084 (1993); Arthur L. Kellerman et al., Suicide in the Home in Relation to Gun Ownership, 327 N. ENGL. J. MED. 467 (1992).

59 R. Green \& Arthur L. Kellerman, Grandfather's Gun: When Should We Intervene? 44 J. Ам. GERIAT. Soc. 467 (1996). The authors also suggest that memory disorders common in dementia make firearm injuries unlikely because the infirm older adult would forget where guns were stored or, if found, how to load and fire them.

6o Stephen Ticehurst et al., Homicidal Behaviour in Elderly Patients Admitted to a Psychiatric Hospital, 3 Dementia 86 (1992) (describing a number of demented patients who exhibited homicidal behavior, most toward their wives); S. Dinnis, Violent Crime in an Elderly Demented Patient, 14 InT. J. Geriat. Psych. 889 (1999) (describing case history of a demented patient who murdered his wife); Michael G. Rayel et al., Dementia as a Risk Factor for Homicide, 44 J. FoRENSIC SCI. 565 (1999) (describing case history of a demented patient who killed his ex-wife with a gun]; Hindley \& Gordon, supra note 45 [describing case history of a demented patient who committed homicide by strangling a fellow resident in a residential care facility).

61 Mario Mendez, Dementia and Guns, 44 J. Ам. Geriat. Soc. 409 (1996) (describing situations in which dementia of moderate severity went undetected by family members of two elderly persons who, in delusional states, shot other people).

62 Final Report, Office of the Medical Inspector, Firearm Access and Automobile Driving among Veterans with Dementia, available at http://www1. va. gov/geriatricsshg/docs/finalrpt. pdf . The government's ability to obtain this sort of information on veterans has been criticized by guns-rights' advocates. See, e.g., Paul Gallant \& Joanne Eisen, An Ominous "Grandfather Clause, "Guns \& Ammo Magazine (Dec. 2000), available at http://www. keepandbeararms. com/information/XcIBViewItem. asp?ID $=1652$

63 Marshal F. Folstein et al., Mini Mental State. A Practical Guide to Grading the Cognitive State of Patients for the Clinician, 12 J. Psychiatric Res. 189 (1975). 
imately one-third (36\%) stated that their guns were kept locked up and 61\% reported that firearms were unlocked. Only $4 \%$ of those with moderate to severe impairment had firearms that were both loaded and unlocked.

A study of outpatients at a university memory disorders clinic examined similar issues. ${ }^{64}$ One hundred and six consecutive outpatients who were referred for symptoms suggestive of dementia were evaluated and their family members were surveyed about the number and loaded status of firearms in the patient's home. The prevalence of firearms in the households of demented family members was high (60.4\%), and there were no differences in rates of gun ownership as a function of the severity of the patient's dementia. Among households with firearms, $44.6 \%$ of families reported that the guns were kept loaded, $38 \%$ did not know the loaded status, and only $16.9 \%$ reported that the firearm was maintained in an unloaded status.

\section{Safety Concerns and Issues of Autonomy}

Access to firearms is only one of many risks to which dementia sufferers are exposed. Older adults who live in homes with gas stoves or fireplaces may forget to turn off a stove or to control a fire. Those who cook for themselves must handle sharp objects. Community dwelling adults who are not adequately supervised may wander away from their homes and get lost, confused when walking in high traffic areas, or suffer injuries from a fall. All older adults, but especially the more infirm, are vulnerable to financial fraud and exploitation. The risks related to older adults' driving are well documented (see infra). In each of these domains, one might hope and expect that family members, caregivers, or health professionals would be aware of the risks posed to older adults and would act to mitigate them and to prevent injuries.

However, providing a safe environment to an older adult can be a challenge, however, particularly in the early to moderate stages of dementia. Alzheimer's disease, in particular, poses complex problems for family members and caregivers, who may not adequately define the problem or seek diagnostic testing to confirm their suspicions. ${ }^{65}$ Even with a diagnosis, families and caregivers are sometimes confused by the fluctuating nature of the disease (e.g., in early or moderate stages of $\mathrm{AD}$, a patient can have periods of lucidity and rational thought). Although there will be progressive loss of memory, judgment, and motor functions, the course is highly variable. In some patients, the demise occurs slowly, sometimes imperceptibly, and over many years. Thus, caregivers and family members find it challenging to match the level of protection with the needs of the older adult. ${ }^{66}$

Perhaps the most complex challenge that arises in these situations is the need to restrict, for reasons of safety, the activities of a person whose identity and self-worth are tied to the normal pursuit of everyday activities. Most adults have acted in an autonomous fashion for decades and passionately desire this independence. However, when functional and cognitive abilities begin to decline, caregivers must intervene to impose restrictions on older adults' activities. Given the nature of the disease, it is often difficult or impossible to appeal to patients' prudence or reason to convince them to with-

64 Karen Spangenberg et al., Firearm Presence in Households with Alzheimer's Disease and Related Dementias, 47 J. Am. Geriatr. Soc. 1183 (1999).

65 David Knopman et al., Patterns of Care in the Early Stages of Alzheimer's Disease: Impediments to Timely Diagnosis, 48 J. Am. Geriat. Soc. 300 (2000).

66 Helen Lach et al., Alzheimer's Disease: Assessing Safety Problems in the Home, 16 Geriat. Nurs. 160 (1995). 
draw voluntarily from dangerous activities, so limitations must be imposed by others. These are not trivial matters and patients and caregivers alike experience sadness, frustration, and dismay at the thought and necessity of limiting the older person's activities, and interpersonal tensions are common. ${ }^{67}$

The majority of dementia patients are cared for at home by family members or caregivers. As a result, most caregivers have limited professional guidance to assist them in planning for the future, or to alert them to the kinds of behavior that the older adult will display as dementia progresses. Thus, they may be perplexed by their inability to gauge when the patient is sufficiently impaired to require limitations on his or her activities. In many cases, there is no formal diagnosis until the disease is fairly well advanced or until long-term residential care is required. In some (but not most) instances, formal adjudication of competency might occur at this point, affecting one's ability to purchase a firearm. ${ }^{68}$

On occasion, informal caregiving systems are absent or fail to provide adequate protection to the older adult or to others in his or her environment. When this occurs and the older adult's abilities to perform the tasks required for independent living are called into question, a clinician may be asked to evaluate the alleged impairments. If the evaluation reveals that an older adult lacks capacity in a particular realm (e.g. financial management), a surrogate decision-maker is needed.

In situations where a durable power of attorney is in place, the person so designated becomes the surrogate decision-maker, responsible for making judgments on behalf of the incapacitated older adult. ${ }^{69}$ When there is no durable power of attorney or healthcare proxy in place or when there is conflict within a family about an elderly relative, guardianship proceedings are sometimes initiated by family members, friends or neighbors, or agencies with whom the older adult has contact. In guardianship proceedings, probate judges must determine whether individuals lack legal competence to care for themselves or their property: in short, to function independently. ${ }^{70}$ The judge thus be-

67 Bruce Jennings, Freedom Fading: On Dementia, Best Interests, and Public Safety, 35 GA L. R. 593 (2001).

68 A diagnosis of dementia by a physician or mental health professional is not synonymous with adjudication of incompetence by a court. Furthermore, a finding by a mental health board that a defendant is mentally ill is not adjudication of mental defectiveness (State v. Hansel, 474 F2d 1120, [1973, Neb. ]) Neither is a finding by a state judge that a person required treatment because he was mentally ill (U.S. v. Vertz, F Supp 2d 787 [2000, MI]).

69 Jennifer Moye \& Dan Marson, Assessment of Decision Making Capacity in Older Adults: An Expanding Area of Practice and Research, 62 J. Gerontology 3(2007).

70 Melanie Gavisk \& Edith Greene, Guardianship determinations by judges, attorneys, and guardians, 25 BeHAv ScI \& LaW (this issue). Judges receive input from a variety of sources to aid them in this decision, including friends and family members, physicians, mental health professionals, caregivers, and occasionally the wards themselves. The information provided by physicians or mental health professionals should involve some sort of formal evaluation of the proposed ward and descriptions of the domains, tasks, and behaviors that pose challenges for the older adult. (Often, though, evaluations lack one or more of these components: Jennifer Moye et al., Clinical Evidence in Guardianship of Older Adults is Inadequate: Findings from a Tri-State Study, Unpublished manuscript, 2006). On the basis of this information, judges must determine whether guardianship or conservatorship (decision-making authority over estate matters) is warranted, in which case a surrogate is appointed to make all relevant decisions for the ward such as housing, healthcare, purchases and sales of property, travel, making or rescinding a will, and entering into contracts. In some instances, a judge may decide that limited, rather than full, guardianship or conservatorship is appropriate, in which case the surrogate's decisions are limited to one or a few realms of decision-making only (e.g. health care or financial management). 
comes the arbiter of the conflict between the right to individual freedoms (e.g. gun possession) on the one hand, and the need to impose restrictions to prevent harm to self or others, on the other hand. This decision is inherently complicated by the fact that judges are forced to make a binary choice-either the older adult is legally competent or is not-about a continuously evolving situation.

Once appointed, guardians are entrusted to make decisions on behalf of the older adult that honor the wishes of the ward. If these wishes are not known, then guardians are to act in the best interests of the individuals they represent. In most instances, this means acting or making decisions that enhance protection of the wards from harm imposed by themselves or by others. The appointment of a guardian typically justifies overriding the ward's interests in autonomy with concerns about safety and well-being.

In general, then, regardless of whether it is a family member, caregiver, judge, or surrogate who has the responsibility to make decisions about the best course of action for the older adult, the task is a complicated one. Patients have good days and bad days and abilities that wax and wane. Thus, it is often unclear when there is sufficient evidence to restrict an individual's rights in the pursuit of safety concerns, when safety trumps autonomy. Complicating matters further is the fact that many older adults have a fervent desire to continue to live independently and make choices for themselves.

What are the implications of guardianship and the autonomy-versus-safety debate for gun owners who become demented? Once guardianship is established (i.e., the ward has been deemed incompetent to manage his or her affairs), laws prohibiting possession of firearms by a "mental defective" presumably apply..$^{71}$ (Of course, whether a caregiver or surrogate decision-maker is made aware of this fact is unknown; thus, we have no data on the frequency with which firearms belonging to persons deemed incompetent are actually taken from them.) But, what about the more nebulous situations in which infirmities are just becoming apparent or in which functionally or cognitively impaired individuals have not been formally evaluated or adjudicated? Just as there are no clear lines that separate decisional capacity from incapacity, there is no clear line that demarcates the point at which an infirm older adult's access to or ownership of firearms should be restricted. Yet situations will inevitably arise in which persons who possessed firearms at a younger age still own and perhaps use their guns (or simply want access to the firearm in order to protect themselves) as they slip slowly and imperceptibly into dementia. How should these situations be handled?

Given our sparse knowledge about the risks posed by firearms in combination with dementia, it is not surprising that few guidelines exist to evaluate the continued use of firearms by individuals whose faculties are in decline. However, because gun ownership in households of dementia patients is relatively high,,$^{72}$ because aggression and violence are not uncommon symptoms of dementia, ${ }^{73}$ and because older adults are at risk for suicide, ${ }^{74}$ reasonable and measured guidelines are, in our opinion, justified and probably overdue. In fact, ownership of firearms by demented patients is already prohibited

71 Gun Control Act, supra note 6. The Federal Gun Control Act serves as a minimum standard; state laws may exceed these mandates. See generally, Survey of State Procedures Involving Firearm Sales Midyear 2003, supra note 12.

72 Spangenberg et al., supra note 64 .

73 Haller et al., supra note 56.

74 Injury and Violence Prevention Unit, supra note 41. 
in some states (e.g. Texas ${ }^{75}$ ), and licensure by dementia patients is explicitly disallowed in others (e.g. Hawaii $\left.{ }^{6}\right)$. In still other jurisdictions, applicants for concealed carry permits must prove their competency. ${ }^{77}$

At the extreme, when perceptual, cognitive, and psychiatric problems have become apparent and when access to firearms could put both the older adult and other innocent people at significant risk, restrictions on continued ownership and use of firearms seem warranted. Some family members and guardians undoubtedly take this action preemptively. ${ }^{78}$

The less extreme cases are more difficult (e.g. when the disease is in its early stages, when the adult in question has significant experience or ability with firearms, or when the older person's identity or sense of safety is closely connected to access to a firearm). Several questions arise in these contexts: Should family members, physicians and caregivers apply "anticipatory intervention" tactics and work to rescind access to the firearm for fear that the individual might cause harm? If so, what should "anticipatory intervention" entail and under what circumstances might it be appropriate? Alternatively, should there be some sort of public health initiative to regulate access to and use of firearms among older adults as now exists in the realm of driving? More generally, can procedures in place to monitor and regulate other activities by older adults provide a template for evaluating gun ownership among people who become functionally or cognitively impaired (but who have not been deemed incompetent)? We turn to the data and policies regulating driving by older adults for a model.

\section{Regulations on Older Adults' Driving}

Considerable attention has been given to the issue of elderly drivers by insurance companies, transportation departments, healthcare providers, and family members alike. Central to this concern is whether and how an elderly driver should be required to hand over the keys; of particular importance are what functional abilities are imperative for safe driving, and how they should be evaluated and monitored in older drivers.

Proponents of regulations and restrictions for older drivers highlight the declining perceptual and cognitive capacities of people in this age group. Obviously, increasing age is often associated with a host of health problems; those central to driving ability include executive dysfunction, restricted peripheral vision, glaucoma and other eye diseases, slowed reaction times, and arthritis and muscle infirmities. ${ }^{79}$ Furthermore, to treat these and other health problems, older adults are often prescribed a complex panoply of medications, which may further interfere with their ability to drive safely.

Driving itself presents certain challenges. One must be able to react quickly and appropriately (e.g. to merge or change lanes) when exposed to stressors (e.g. other drivers, pedestrians, or objects in the road) that occur simultaneously and unexpectedly. Drivers-including older drivers-who are unable to effectively meet these demands are

75 Tex. Penal Code Ann. § 46.01 (2004) et seq.

76 Haw. Rev. Stat. § 134-1 (2003) et seq.

77 E.g., Or. Rev. Stat. § 166.291 (1993); Alaska Stat. § 18. 65.715(b) (1994).

78 Supra.

79 Reed Karaim, When Is It Time To Quit Driving? AARP B., Nov. 2006, at 10. 
likely to create hazardous conditions on the road and to be more susceptible to accidents and ensuing injuries.

Elderly drivers have unique challenges, as well. For example, many older drivers experience "pedal confusion" (confusing the brake and gas pedals). Recent research suggests executive dysfunction is an important contributor to this confusion and thus to unsafe driving. ${ }^{80}$ For example, an elderly Santa Monica man who drove his car into the local farmers' market in 2003, killing 10 people and injuring 63 others ${ }^{81}$ and an elderly Massachusetts woman who veered her car off the road and into a house in $2006^{82}$ both attributed their accidents to confusing the gas pedal for the brake pedal.

Elderly drivers pose safety risks both to others and to themselves. Though older drivers have low accident rates per capita, they are second only to teenagers in per-mile fatal crash rates. ${ }^{83}$ In part, these casualties are related to the physical frailty of older drivers, whose bodies are less able to withstand the physical trauma suffered in automobile accidents. ${ }^{84}$ And as our society continues to age, it is expected that rates of motor vehicle accidents and fatalities among older adults will also continue to rise.

Many states have enacted driver licensing regulations and restrictions on older drivers in an effort to reduce accidents. Twenty-seven states have mandatory testing for drivers 70 years of age or older. ${ }^{85}$ Though testing standards vary by state, the procedures generally include one or more of the following: a shortened time period between license renewals, ${ }^{86}$ in-person renewals ${ }^{87}$ and vision tests. ${ }^{88}$ For example, Kansas ${ }^{89}$ and Maine ${ }^{90}$ require license renewals starting at the age of 65 and subsequently every four years thereafter. The shortened time periods between renewals are in place to identify rapid decrements in physical and mental health of aging adults; they may serve as checks on one's ability to drive safely. Empirical evaluations of these mandates have shown positive outcomes. Researchers have found, for example, that in-person renewals ${ }^{91}$ and vision tests are associated with lower fatality rates for older drivers. ${ }^{92}$

80 See Safe Mobility Of Older Persons, Transportation Research Board, 2004 (2006), available at http://www. crag. uab. edu/safemobility/NewsletterNov04. doc

81 See Wikipedia, George Russell Weller, 2006 (2006), available at http://en. wikipedia. org/wiki/George Russell Weller

82 Proposed Laws would Tighten License Access for Older Drivers (Oct. 14, 2006), available at www. gazettenet. com/newsroom

83 David C. Grabowski et al., Elderly Licensure Law and Motor Vehicle Fatalities, 291 JAMA 2840 (2004); see US Dept of Transportation, Federal Highway Administration, Older Driver SAFETY FACTS \& StATistics, 2006 (2006), available at http://safety. fhwa. dot. gov/older driver/ older facts. htm

84 Joseph F. Coughlin et al., Who Drives Older Driver Decisions?, 2004 (2006), available at http://web. mit. edu/agelab/news_events/pdfs/AgeLab_driver_decision.pdf

85 Karaim, supra note 79.

86 E.g., IA Stat. § 321.186A (1999); RI Stat. § 31-10. 3-13 (1986); SC Unann. Code § 56-1-210 (2006).

87 E.g., AK Statute § 28.15.101 (1978); CO Rev. Stat., Title 42, Article 2, Part 1 (1995); ID Title 49, Chapter 3, 49-319 (no date).

88 E.g., AZ Rev. Stat., Chapter 8, Article 4, 28-3171 (no date); HI Stat. § 286-240 (1970); MT Ann. Stat. Title 61, chapter 5, 111 (2005).

89 KS Stat. § 8-235d (2000).

90 ME Chapter 11, subchapter 4, § 1406 (2003).

91 In-person renewal requirements allow inspectors to refuse to renew licenses to drivers who are obviously impaired or require a medical evaluation prior to granting a renewal.

92 Grabowski et al., supra note 83. 
Some states implement even more stringent regulations concerning elderly drivers. Minnesota, for example, is one of eight states requiring that older drivers demonstrate sound knowledge of the rules of the road and the ability to apply that knowledge in specific driving situations. ${ }^{93}$ The standards in Minnesota require competency in written and road tests, and evaluative research in the state has shown that elderly drivers with dementia demonstrate a significantly poorer knowledge of driving regulations. ${ }^{94}$ Older drivers who are unable to pass all three parts of the knowledge test do not progress to the road examination and consequently forfeit their licenses. 95

In other states, the responsibility for noting driving concerns is attached to people other than older drivers themselves. Nine states have enacted legislation holding doctors and other medical professionals to mandated reporting requirements for patients who may pose a driving risk due to diminished mental and/or physical capabilities (e.g., dementia attributable to Alzheimer's disease). ${ }^{96}$ In these states, doctors and medical professionals can be held legally responsible for injuries incurred by either the driver or a victim if a patient is involved in an injury-causing accident. ${ }^{77}$ This legislation reflects a growing trend in which third parties (e.g., family members, caregivers, healthcare providers) are responsible for recognizing when an elderly person becomes a threat to himself or herself and to others by continuing to drive..$^{8}$

Despite these regulatory schemes, the issue of when to stop driving and how and when to insist that another person "hand over the keys" is often a sensitive one, as most adults associate driving with autonomy and competency, ${ }^{99}$ but the interests of safety oftentimes override individual pursuits of freedom and pleasure. Aware of the delicacy of the issue, some states (e.g. Missouri) have also granted legal confidentiality for family members or doctors who report inept drivers to state licensing agencies. ${ }^{100}$

\section{Policy Recommendations and Research Directions}

\section{Policy Recommendations}

Regulations placed on older adults' driving can serve as a model for dealing with situations where individuals may pose a threat to themselves or others by possessing and using a firearm. Gun ownership is undeniably a more fundamental right (in light of the Second Amendment) than driving and one that many people would fight to retain, yet driving and firearm access share a common feature: both provide a sense of independence and autonomy. However, we suspect that if older adults were forced to

$93 \mathrm{MN} \S 171.04$ (2005).

94 Geri Adler et al., Driving SAFE: Development of a Knowledge Test for Drivers with Dementia, 5 Dementia 213 (2006). 95 Id.

96 E.g., DE Title 21, § 27 (1) 2707 (2006); NV N. R. S. § 483.250 (2006); PA § 83.6 (2004).

97 Physicians can also be held liable for accidents and subsequent injuries if a physician fails to advise a patient about medication side-effects or physical or psychiatric conditions that can result from taking a particular medicine. See Jeffrey L. Metzner, Commentary: Driving and Psychiatric Illness, 32 J. AM. Acad. Psychiatry Law 80 (2004); Grabowski et al., supra note 83.

98 Grabowski et al., supra note 83 .

99 Richard A. Marottoli et al., Driving Cessation and Increased Depressive Symptoms: Prospective Evidence from the New Haven EPESE, 45 J. Am. Geriat. Soc. 202 (1997).

100 Hot Topics, Older Drivers; Mo. Rev. Stat. § 302.291. 
choose between handing over their firearms and handing over their car keys, many, if not most, would opt for the former over the latter. Most people would agree that regulating and restricting driving among older adults who may lack requisite abilities is a necessary and important aspect of ensuring public welfare. We believe that concerns about public safety should also loom large in decisions about continued firearm ownership by impaired older adults, whether or not a judge has deemed this person incompetent or a physician has diagnosed dementia. In particular, a policy of reevaluating firearm licenses at some regular interval (and with a shortened interval after the age of 65) seems reasonable. These evaluations should require, at a minimum, demonstrated proficiency in use of a firearm, vision testing, and some brief cognitive testing (e.g. Mini Mental Status Exam) to establish baseline and subsequent levels of functionality.

One example of such a system is provided by legislation enacted in New Jersey that requires specialized testing of retired law enforcement officers who wish to maintain their firearms. ${ }^{101}$ According to state law, retired officers can be eligible to carry a handgun provided they are able to meet certain requirements, including demonstrating that they had been full-time law enforcement officers who retired in good standing, and that they are less than 70 years old, proficient with a handgun, and able to provide proof of semi-annual qualification with this gun. They must also pass a test demonstrating their knowledge of New Jersey criminal codes, answer questions about their psychological well-being, and authorize a search of their mental health records.

Given the expected increase in the incidence of dementia in the population and the relatively high rate of gun ownership in households of dementia sufferers, it would behoove us to begin to have open and candid discussions about public safety issues related to firearm availability in old age. We believe that governmental, public health, and law enforcement officials should lead the way in increasing public awareness about these serious safety concerns through written materials and educational programming. Ideally, these educational efforts would detail the potential dangers as well as strategies for safe use and storage of firearms and warning signs that family members should attend to as they strive to provide safe environments for older adults. The Geriatrics and Extended Care Strategic Healthcare Group of the Department of Veterans Affairs has produced an informational packet that briefly explains the nature of dementia, the relationship between availability of firearms and incidence of suicide, and the role that family members should play in preventing firearm-related violence. ${ }^{102}$

Healthcare providers (including physicians, psychologists, therapists, and social workers) have a more direct role to play in educating patients and their families about the risks of firearm availability. ${ }^{103}$ After determining that an older adult has access to a

101 See Firearms Information, New Jersey State Police Office of the Attorney General, Retired OfFicers Right to CARrY, 1997 (2006), available at http://www. state. nj. us/njsp/about/fire ret. html

102 Final report, Office of the Medical Inspector, supra note 62. The pamphlet contains the following advice: The best way to reduce gun risks is to remove the gun from your home. If you keep a gun: Keep your guns in a sturdy locked cabinet that does not have glass. Always store guns unloaded. Install trigger guards on all guns to prevent them from being used. Keep all ammunition in a locked fireproof safe in a separate place from the guns. Keep the keys for the trigger guards, gun cabinet, and ammunition hidden from children and persons with dementia. The safest action is to get rid of the guns. Store them at a neighbor's house, sell them, or take them to the police to be destroyed. If you keep guns in a home where someone with dementia lives, the lives you risk may be your own as well as other family and friends. If you have questions regarding gun safety, please see your care provider. 
firearm, the provider who suspects some cognitive impairment should initiate evaluation of the client and develop a plan for working with family members to confront, supervise, or exhort the older adult to relinquish access to a firearm. ${ }^{104}$ Physicians have a duty to intervene if they believe that the client has suicidal or homicidal tendencies. The clinician can also provide concrete advice to the family about what to do if the patient is resistant. A law that requires physicians or psychologists to report to licensing bureaus all confirmed diagnoses of dementia might be considered, so that gun permits of individuals seriously impaired by dementia can be revoked or stringent re-licensing requirements implemented. ${ }^{105}$ Mental health professionals are sometimes asked to evaluate or certify a patient for firearm ownership; obviously, they need to be cognizant of issues related to declining cognitive and functional abilities. Professional medical and mental health organizations should thus become proactive in educating their members about the importance of asking patients and family members whether firearms are present in the homes of dementia sufferers, whether the firearms are accessible to patients, and how they are secured.

Finally, we would advocate increased reliance on "cognitive physicals" or "cognitive check-ups" as screening tools for high risk older adults. ${ }^{106}$ Ideally, this procedure would involve an evaluative component, a diagnosis (if relevant), and translation of the results into domain-specific, functional strengths and limitations. Specific recommendations would follow and might deal with the reasonableness of continued access to firearms and steps that family members could take to reduce the likelihood of unsafe behaviors.

\section{Research Directions}

In terms of research directions suggested by our analysis, several ideas come to mind. First, additional epidemiological research on the prevalence of firearms in the homes of older adults and the frequency of their use would be helpful. These data would provide a clearer picture of the extent to which these issues will be problematic as our population ages and the incidence of dementia increases. Some more specific data that outline the relative risks of firearm usage by people with impaired cognitive and func-

103 Primary care providers might serve as the front line, given that the vast majority of older suicide victims had been under the active care of a primary care provider during the last 30 days of their lives. J. Luoma et al., Contact with Mental Health and Primary Care Prior to Suicide: A Review of the Evidence, 159 Am. J. Psychiatry 909 (2002).

104 Green \& Kellerman, supra note 59.

105 Clinicians should also become knowledgeable of any mandatory reporting requirements in their states (Donna M. Norris et al., Firearm Laws, Patients, and the Roles of Psychiatrists, 163 Aм. J. Psychiatry 1392 [2006]). Jennings (supra note 67) details objections to this kind of broad brush approach in the context of drivers license renewals, pointing out the lack of standardized and uniform diagnostic criteria and testing procedures, and suggesting that individuals with mild cognitive impairment who seek out an early diagnosis so as to benefit from therapeutic interventions, may be subjected to "more restrictions on their choices and behavior than those who remain invisible to medical surveillance in the community, but whose level of impairment might actually be worse," at 602-603. Similar concerns apply to gun ownership: mandatory reporting may deter some patients from seeking medical care early in the progression of Alzheimer's disease, when diagnosis and treatment can be most helpful. It would also place an additional burden on physicians.

106 Moye \& Marson, supra note 69. 
tional abilities would also be helpful, as would data that describe the kind and level of risk that caregivers and others face when older adults have access to firearms.

It would also be useful to know when aggression and violence are most likely to occur in dementia patients so that they could be averted to the extent practicable. Early findings suggest that patients admitted to a geriatric psychiatry ward favored a "shoot first. . . and ask questions later" approach, and that violence tended to occur in conjunction with profound confusion or delusional beliefs. ${ }^{107}$ Other research suggests that aggressive behavior in people with dementia is related to the need to remove a perceived threat, as might occur when the patient is receiving intimate care (e.g. being bathed). ${ }^{108}$ This finding also raises the intriguing possibility that caregivers can inadvertently trigger or contribute to aggressive behaviors in dementia patients by the manner in which they communicate and interact with them, a result that merits further examination. ${ }^{109}$

Violent behaviors perpetrated by dementia patients raise complex and fascinating public policy questions about liability for injuries caused by these behaviors, including the extent to which caregivers may be liable. ${ }^{110}$ Little is known about the extent of or justification for this concern, and research exploring it would be warranted.

From a clinical assessment perspective, it would be useful to know how clinicians currently evaluate capacity issues related to home safety generally, and to firearm access specifically. One might determine, for instance, whether there are assessment tools that are routinely used to aid in this process and to what extent they are reliable and valid.

Finally, it seems important to evaluate the effectiveness of the few on-going attempts to educate the public about firearm issues related to older adults and to devise and evaluate additional outreach efforts. To our knowledge, there is no widely disseminated information on this topic. (Apparently, the sole example at this point is the informational campaign conducted by the Veterans Administration ${ }^{111}$-which obviously does not reach the millions of older Americans who are not veterans, and whose effectiveness has not been confirmed.) Obviously, some clinicians discuss these matters with their patients and the patients' families. Do they do so effectively?

\section{Conclusion}

The number of guns owned by older adults is almost certainly increasing as the U.S. population ages, though it is also clear that "offenses committed by the elderly do not in any sense constitute a "crime wave." ${ }^{112}$ Nonetheless, "[t]he seriousness of the prob-

107 William M. Petrie et al., Violence in Geriatric Patients, 248 JAMA 443 (1982).

108 Wilaipun Somboontanont et al., Assaultive Behavior in Alzheimer's Disease: Identifying Immediate Antecedents During Bathing, 30 J. Gerontological Nurs. 22 (2004).

109 Kristi Skovdahl et al., Different Attitudes When Handling Aggressive Behavior in Dementia: Narratives From two Caregiver Groups, 7 Aging \& Mental Health 277 (2003).

110 Edward Richards, Public Policy Implications of Liability Regimes for Injuries Caused by Persons with Alzheimer's Disease, 35 GA L. R. 621 (2001).

111 Office of the Medical Inspector, supra note 62.

112 Evelyn S. Newman \& D. J. Newman, Public Policy Implications of Elderly Crime, in ELDERLY CRiminals (E. S. Newman et al. eds., 1984), at 226. 
lem is not in its magnitude, present or projected; the significance of the problem is its uniqueness." 113 Because of the special circumstances concerning crime, and especially violent crime, committed by older adults, as well as a criminal justice system geared more toward young offenders, this largely hidden issue raises a host of questions about economic, social, and justice policies. ${ }^{114}$

There are obvious costs associated with our proposals that older adults receive periodic "cognitive check-ups" and that governmental and public health agencies undertake informational campaigns to make people aware of the risks of continued firearm access in old age. A system that requires older adults to pay some portion of the costs for the proposed evaluations (of both their cognitive abilities and their ability to maintain a firearm license) could weigh disproportionately on the poor and deter others from complying. Some would argue that no one has the right to decide for an elderly person in failing health whether he should live or use a gun to take his own life. We acknowledge these concerns, yet we also advocate that this largely hidden issue be brought to light as the population of older adults with dementia and with access to firearms proliferates.

113 Id.

114 Id. at 226-235. 